\title{
Independent Life Skills among psychosocial care network users of Rio Grande do Sul, Brazil
}

\author{
Habilidades de Vida Independente de usuários da rede de atenção \\ psicossocial do Rio Grande do Sul, Brasil
}

\author{
Cândida Garcia Sinott Silveira Rodrigues ${ }^{1}$ \\ Vanda Maria da Rosa Jardim ${ }^{1}$ \\ Luciane Prado Kantorski ${ }^{1}$ \\ Valeria Cristina Christello Coimbra ${ }^{1}$ \\ Carlos Alberto dos Santos Treichel ${ }^{1}$ \\ Beatriz Francchini ${ }^{1}$ \\ Andreia Ferreira Bretanha ${ }^{1}$ \\ Aline dos Santos Neutzling ${ }^{1}$
}

\footnotetext{
${ }^{1}$ Departamento de Enfermagem, Faculdade de Enfermagem, Universidade Federal de Pelotas. R. Gomes Carneiro 1, Porto. 96010610 Pelotas RS Brasil. candidasinott@hotmail.com
}

\begin{abstract}
This is a cross-sectional study that aims to identify the prevalence of lower independent living skills and their associations in 390 users of psychiatric community-based services in the state Rio Grande do Sul, Brazil. For tracing the outcome it was used the "scale Independent Living Skills Survey", adopting a cut-off value lower than 2. The crude and adjusted analyses were conducted on binary logistic regressions and they considered a hierarchical model developed through a systematic literature review. In adjusted analysis the level of the same variables were adjusted to each other and to previous levels. The statistical significance remained as a $0.05 p$-value. The prevalence of smaller independent living skills was $33 \%$ and their associations were: younger age; no partner; lower education; resident at SRT; diagnosis of schizophrenia and younger diagnosis.
\end{abstract}

Key words Personal autonomy, Independent life, ILSS-BR, CAPS, SRT
Resumo Este estudo transversal objetiva identificar a prevalência de menores habilidades de vida independente e suas associações em 390 usuários de serviços comunitários de saúde mental no estado do Rio Grande do Sul, Brasil. Para delimitar o desfecho, a escala "Independent Living Skills Survey" foi utilizada adotando-se como ponto de corte valores menores que 2. Análises brutas e ajustadas foram conduzidas por regressão logística binária que considerou um modelo teórico hierarquizado desenvolvido a partir de uma revisão sistemática de literatura. Na análise ajustada as variáveis do mesmo nível foram ajustadas entre si e com as do nível anterior. Significância estatística foi considerada como p-valor $<0,05$. A prevalência de menores habilidades de vida independente foi de 33\% e suas associações foram: menor idade; não possuir companheiro; menor escolaridade; residência no SRT; diagnóstico de esquizofrenia e menor tempo de diagnóstico.

Palavras-chave Autonomia pessoal, Vida independente, ILSS-BR, CAPS, SRT 


\section{Introduction}

Behavioral and mental disorders hit 450 million people over all countries, causing individual and social suffering. According to World Health Organization around $25 \%$ of world population develop mental disorders during their lives and these mental disorders represents $12 \%$ of the world disease load ${ }^{1}$.

These disorders cause significant impacts in the social life which are composed by: economic responsibilities, psychosocial, Family life, individuals, ruptures and disorganization in everyday and job routines, lost of productivities and treatment expenses. There are also others aspects that are difficult to identify which are relative to life quality, discrimination, stigma and lost opportunities in social, job and leisure relations ${ }^{2}$.

Since 1970s, in Brazil, the critic about the traditional psychiatric has changed the concept of caring object that were focused in the illnesses to an approach which overcomes the dichotomy between health/illnesses, individual/social, so the asylum model of caring was broke and replaced by a psychosocial rehabilitation perspective ${ }^{2}$.

According to Pinho et al. ${ }^{3}$ the transformation of psychiatric asylums practices into psychosocial rehabilitation resets itself as a knowledge that allows to consider the psychiatric disorder as one more data in the individual. Therefore, there is this individual who has a severe and persistent disorder, but beyond that it lives in a territory, establishes social relations and is part of a particular family.

Aiming to provide recovery opportunities and minimize disabling community chronicles effects, services that focus on psychosocial rehabilitation, such as therapeutic residential services (SRT) and the Centers for Psychosocial Care (CAPS), developed strategies that promote social reintegration and rescue lost skills, giving the individual the opportunity to live independently $y^{4,5}$.

In this situation, it is of a great value for these health services to identify the skills levels of patients, in different areas of everyday life in purpose to determine the most relevant objectives for the rehabilitation programs, increase the efficacy of critic decisions in patients' treatment and then monitoring the effects in patients' life $^{6,7}$.

In this point of view, this research aims to identify the prevalence of lower independent living skills and their associations among users of community mental health services in the state of Rio Grande do Sul.

\section{Methodology}

This is a cross-sectional study clipping a mental health community-based service evaluation researched in 2009 in Rio Grande do Sul, Brazil (REDESUL).

The research was submitted to the ethics committee in research of Dentistry school (Federal University of Pelotas) that was positive to its implementation by the report $073 / 2009$. The report is in accordance with the ethical procedures required for research with human beings, conforming the constant of Resolution 196/96 of the National Health Council and is suitable for the envisaged by Resolution 466/12.

The research named REDESUL had as general objective evaluate aspects related to brazilian psychiatric reform in the psychosocial care networks (RAPS) in the state of Rio Grande do Sul. Was adopted as an indicator of a complete RAPS the existence of residential therapeutic service, in this sense, all municipalities of Rio Grande do Sul which have residential therapeutic service were included, they are: Alegrete, Bagé, Caxias do Sul, Viamão and Porto Alegre.

The sample was calculated using the software Epi Info 6.04 considering an alpha value of $5 \%$ and power of $80 \%$. The result value was increased in $20 \%$ to control confusing factors and losses; the final sample comprised 390 individuals. The selection of respondents prioritized SRT users and sequentially intensive CAPS users and semi-intensive CAPS users proportionally. All studied individuals had institutional bond with the services were the research was conducted.

Data collection was performed by interviewers previously selected and qualified by a training of 40 hours held by the coordinators of the research. Quality control was carried out in the encoding of data collection instruments; in the review conducted by supervisors to receive the questionnaires; in the replication of $5 \%$ of the interviews.

The purpose of measuring the degrees of daily life skills of psychiatric patients were used the scale Independent Living Skills Survey (ILSS) ${ }^{8}$. It is a Likert scale of 5 points $(0=$ never, $1=$ sometimes, $2=$ normally, $3=$ often, $4=$ always). Calculating the main score of answers, which indicated a better result when closer to 4 , did the measurement. As in other researches ${ }^{9,10}$, the outcome of the scale was dichotomized in order to characterize the individuals according smaller or larger independent living skills. The cut-off value 
adopted was 2 because it considers the difference between those who often have good performance of those who rarely or never have.

Using a multivariate logistic regression was evaluated the association between the independent variables and lower independent living skills (Less than 2 points on the scale).

For producing reliable data, as in other researches $^{6,9}$, the 84 questions of ILSS-BR were exclusively answered by the patients caregivers, the other questions were answered by the users of the health services.

The proposed analysis was guided by an hierarchical theoretical model that considered the first level socio-demographic variables, including: gender, age (up to 39 years, 40 or more), marital status (with partner; without partner), skin color (white, brown; black; other), education (0-8 years, 9 years of education or more), source of income (formal or informal employment; retirement, pensioner; family income; aid) and living conditions (own house or rented; Pensions/family/friends; SRT).

In the second level, the variables included diagnosis (depression, bipolar disorder, schizophrenia, other disorders; do not know), presence or absence of non-psychiatric morbidity, health condition perception (very good, good, regular, bad), time of diagnostic ( 21 to 41 years old, 6 to 20; 0 to 5 years),

At the third level were included social and Family support variables, including amount of friends (11 or more friends; 5-10 friends, 1-4 friends; no friends) and number of relatives with whom they can talk about any subject ( 6 or more relatives; 1 -5 relatives; none).

Already in the proximal level, were inserted mental caring health characteristics variables, such as: type of service (SRT; CAPS), type of treatment (semi-intensive CAPS, CAPS intensive; SRT), time using the service (over 5 years, 3-5 years, 1-3 years, less than 1 year), difficult accessing the service (never, rarely, sometimes, always, almost always) and last year psychiatric crises (no, yes).

The analyses were conducted with Stata 11 package (Stata Corp., College Station, United States). In crude analysis the variables were identified to compose the hierarchical analysis mod$\mathrm{el}(\mathrm{p}<0.2)$. In adjusted analysis the level of the same variables were adjusted to each other and those associated to previous levels than those kept the model for confusing control. Statistical significance remained as a $<0.05 \mathrm{p}$-value.

\section{Results}

The studied sample had 390 subjects which 120 of these were SRT users, 134 were intensive CAPS users and 134 semi intensive CAPS users (20 subjects had used CAPS and SRT concomitantly). The sample was comprised majority by males $(52.6 \%), 40$ years or more $(62.4 \%)$, White self-declared (55.2\%) and single (78.6\%).

The prevalence of individuals with lower independent living skills (those who had overall scores lower than 2 in ILSS-BR scale) was 33\%.

After variable crude analysis proposed by the theoretical model, the variables that were associated with the outcome with a value of $\mathrm{p}<0.2$ were kept. At this stage skin color $(\mathrm{p}=0,34)$ and last year crisis variables were excluded.

In the adjusted analysis, variables regarding the source of income $(p=0.87)$ gender ( $p$ $=0.64)$, health status perception $(\mathrm{p}=0.21)$, non psychiatric morbidity $(\mathrm{p}=0.87)$, number of friends $(p=0.33)$, number of relatives with whom they can talk about any subject $(\mathrm{p}=0.72)$, accessibility difficulty $(p=0.20)$, the service age $(p=0.44)$, type of treatment $(p=0.24)$ and type of service ( $p=0.31)$ lost strength of association.

The variables results that remained associated with the outcome can be seen on Table 1, there are available data about the prevalence of smaller independent living skills, crude and adjusted odds ratios and their respective $\mathrm{p}$-values.

\section{Discussion}

The prevalence of persons who had lower degree of independent living skills in the studied population was 33\%. Other researches in Brazil that used ILSS-BR presented scale scores for each of the nine subscales, however, they did not present the overall score, so it is difficult compare the results.

However, comparing with previous researches the majority of the subscales presented a high prevalence of persons with smaller independent living skills. As an example, in the study developed by Dias ${ }^{11}$ in the items: domestic activities; preparation and storage of food; money management; transport; leisure and employment the prevalence varied between $71.8 \%$ and $84 \%$. Or even in Abelha's et al. ${ }^{12}$ studies presented the prevalence between $65.4 \%$ and $97 \%$ in same items in individuals with lower abilities.

Comparing the results with the persons analyzed by Dias ${ }^{11}$ and Abelha et al. ${ }^{12}$, the persons of this research showed better independent living 


\begin{tabular}{|c|c|c|c|c|c|c|c|}
\hline \multirow[t]{26}{*}{ 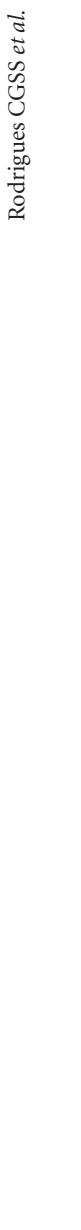 } & $\begin{array}{l}\text { Table } 1 . \text { Prevalence and } \mathrm{Odc} \\
\text { according to variables }(\mathrm{N}=\end{array}$ & $\begin{array}{l}\text { ratio } \\
\text { 90). }\end{array}$ & s of lower inc & dependent life skills in & SRT and $\mathrm{C}$ & CAPS users of Rio Grand & de do Sul \\
\hline & & $\mathbf{N}$ & Prevalence & OR Crude / IC (95\%) & $\mathrm{P}$-value $\mathrm{C}$ & DR Adjusted / IC (95\%) & P-value \\
\hline & Age & & & & 0,012 & & 0,036 \\
\hline & Until 39 & 133 & $39,1 \%$ & 1 & & 1 & \\
\hline & 40 or over & 221 & $26,2 \%$ & $0,55(0,35-0,87)$ & & $0,47(0,28-0,80)$ & \\
\hline & Marital Status & & & & 0,002 & & 0,037 \\
\hline & With Partner & 83 & $19,3 \%$ & 1 & & 1 & \\
\hline & No Partner & 305 & $36,7 \%$ & $2,43(1,34-4,39)$ & & $2,34(1,16-4,73)$ & \\
\hline & Education & & & & 0,007 & & 0,045 \\
\hline & 9 or + years of education & 95 & $18,9 \%$ & 1 & & 1 & \\
\hline & 8 or - years of education & 221 & $33,5 \%$ & $2,15(1,20-3,86)$ & & $2,19(1,18-4,09)$ & \\
\hline & Home & & & & 0,018 & & 0,019 \\
\hline & Own or rent house & 201 & $26,9 \%$ & 1 & & 1 & \\
\hline & Family house & 71 & $35,2 \%$ & $1,47(0,82-2,63)$ & & $1,54(0,81-2,95)$ & \\
\hline & SRT & 108 & $42,6 \%$ & $2,01(1,23-3,30)$ & & $2,29(1,20-4,36)$ & \\
\hline & Diagnosis & & & & $<0,001$ & & $<0,001$ \\
\hline & Depression & 64 & $6,2 \%$ & 1 & & 1 & \\
\hline & Bipolarity & 39 & $17,9 \%$ & $3,28(0,89-12,05)$ & & $3,21(0,86-11,98)$ & \\
\hline & Schizophrenia & 72 & $37,5 \%$ & $9(2,94-27,55)$ & & $9,30(2,99-28,88)$ & \\
\hline & Others & 34 & $35,3 \%$ & $8,18(2,38-28,06)$ & & $8,83(2,47-31,67)$ & \\
\hline & Do not know & 164 & $43,3 \%$ & $11,45(3,97-32,99)$ & & $8,22(1,89-35,62)$ & \\
\hline & Time of Diagnostic & & & & $<0,001$ & & 0,101 \\
\hline & +20 years & 57 & $15,8 \%$ & 1 & & 1 & \\
\hline & 6 to 20 years & 87 & $25,3 \%$ & $1,80(0,76-4,27)$ & & $2,58(0,95-6,99)$ & \\
\hline & until 5 years & 60 & $28,3 \%$ & $2,11(0,58-5,22)$ & & $3,04(1,09-8,51)$ & \\
\hline & Do not know & 184 & $43,5 \%$ & $4,10(1,90-8,85)$ & & $3,29(0,93-11,61)$ & \\
\hline
\end{tabular}

Source: REDESUL, 2009.

skills. However, it is important that both Dias ${ }^{11}$ as Abelha et al. ${ }^{12}$ analyzed residents of institutions for people who already had a long history of hospitalization and lost their family relationships.

The Family relationship is an important factor on the final results. Adjusted analysis showed 2.29 times higher probabilities of presenting smaller independent living skills among SRT users (residents) compared to those living in their own homes. It is emphasized that the SRT is a service that works in the same perspective that welcomes individuals who were hospitalized for many years and ended up losing contact with their families.

The adjusted analysis showed that older age was a protection factor for the final outcome. Individuals aged 40 years or over had 53\% less chance to be identified as individuals with smaller independent living skills than younger individuals. Seems to be a progression on the chances to present the outcome on more recent diagnosis. Compared to those diagnosed for over 20 years, individuals diagnosed five years ago or less had
3.04 more chances to be identified with smaller independent living skills.

These data provide the basis to suggest that over the years individuals can develop more independent living skills.

Reaffirming the projection that projects which deal with the purpose of psychosocial rehabilitation, psychiatric suffering acts as one more element of life of the individual, but does not define itself ${ }^{3}$. Once the individual is in social and family contact, it has the opportunity to have better understanding of its own functioning and consequently develop and improve their skills.

Vidal et al. ${ }^{13}$ also reported that the prospect that community-based services favor the development of independent living skills, in his study the results indicate that after 2 years living in community, patients has showed significant improvement in almost all subscales scores of the ILSS-BR. Dias ${ }^{11}$ also evaluated a group of SRT users at different times with an interval of two years and he found better results in 7 of the 9 subscales of the ILSS-BR. 
Regarding marital status, it is possible to affirm that individuals who had no partner the chances of presenting the outcome were 2.34 times higher than those who had a partner. It is worth to notice the importance of family relationships provided by health community services, as well as the need to promote actions that will approach the user's family of its treatment.

Lower education has shown to be a factor risk for the final outcome. Individuals with education of eight years or less study showed 2.19 times more chances to present a bad outcome compared to those who had for nine years or more of education. The analyzed sample had $70 \%$ of individual with less than nine years; consequently they have at most basic education finished. In this reality, actions that help the user to continue studying would be an excellent alternative to support the development of citizenship, and independent living skills of subjects who attend the service.

Diagnosis showed a lower prevalence of the outcome in individuals diagnosed with depression $(6.2 \%)$, while the prevalence for those who presented bipolar disorders was $17.9 \%$, and schizophrenics $37.5 \%$. Although these data reflects the limitations offered by each diagnosis characteristics, also it calls attention that individ- uals who did not know answer their own diagnosis the prevalence of smaller independent life skills was $(43.3 \%)$.

One limitation of this research was the date of collection; however, its results still constitute an important discussion and reflection about issues related to psychosocial rehabilitation and autonomy of individuals with mental disorders in Brazil. One of its goals is to have the overall score of independent living skills hardly resented in other articles on the same subject.

\section{Conclusion}

After all it was concluded that most relevant factors associated with smaller independent living skills in the analyzed sample are: age; no partner; low education; residence at SRT; diagnosis of schizophrenia and younger diagnosis.

It is important for services in psychosocial rehabilitation of individuals with mental disorders when they plan their actions it would be interesting that CAPS and SRT's interpreted the studied characteristics and as an strategies, as an example promote actions to stimulate educational issues and an expansion of user's social and family relationships.

\section{Collaborations}

CGS Silveira-Rodrigues worked at design, analysis, interpretation of data and elaborating the article. VMR Jardim worked at design, analysis and interpretation of data. CAS Treichel worked on the analysis and interpretation of data, supporting the elaboration. LP Kantorski, VCC Coimbra, AF Bretanha, AS Neutzling and B Franchini worked in the critical review. 


\section{References}

1. Organización Mundial de la Salud (OMS). Departamento de Salud Mental y Toxicomanías. Atlas de salud mental en el mundo 2001. Determinantes de la Salud Mental y Poblaciones. Ginebra: OMS; 2001.

2. Yasui S. Rupturas e Encontros: desafios da Reforma Psiquiátrica Brasileira. Rio de Janeiro: Editora Fiocruz, 2010.

3. Pinho PH, Oliveira MAF, Vargas D, Almeida MM, Silva ALA, Colvero LA, Barros S. Reabilitação psicossocial dos usuários de álcool e outras drogas: a concepção de profissionais de saúde. Rev. Esc. Enferm. USP 2009; 43(spe.2):1261-1266.

4. Barreto MS, Buchelle F, Coelho EBS. O cuidado com o sofredor psíquico institucionalizado. Cogitare Enferm 2008; 13(4):607-611.

5. Campos GWS, Onocko-campos RT, Del Barrio LR. Políticas e práticas em saúde mental: as evidências em questão. Cien Saude Colet 2013; 18(10):2797-2805.

6. Bandeira M, Lima LA, Gonçalves S. Qualidades psicométricas no papel da Escala de Habilidades de Vida Independente de pacientes psiquiátricos (ILSS-BR):fidedignidade do teste e do reteste. Rev. Psiq. Clín. 2003; 30(4):121-125.

7. Harvey PD, Stone L, Lowenstein D, Czaja SJ, Heaton RK, Patterson TL. The Convergence between Self-reports and Observer Ratings of Financial Skills and Direct Assessment of Financial Capabilities in Patients with Schizophrenia: More Detail is Not Always Better. Schizophr Res 2013; 147(1):86-90.

8. Wallace CJ. Functional Assessment in Rehabilition. Schizophr Bull 1986; 12(4):604-623.

9. Wagner LC, Fleck MPA, Wagner M, Dias MTG. Autonomy of long-stay psychiatric inpatients. Rev Saude Publica 2006; 40(4):699-705.

10. Abelha L, Muñoz MD, Gonçalves S, Fagundes P, Barbosa DR, Legay LF, Lovisi G. Evaluation of social disablement, psychiatric symptoms and autonomy in long-stay psychiatric patients. Rev. psiquiatr. clín. 2006; 33(1):10-17.

11. Dias MTG. A reforma psiquiátrica brasileira e os direitos dos portadores de transtorno mental: uma análise a partir do serviço residencial terapêutico morada São Pedro [tese]. Porto Alegre: Faculdade de Serviço Social; 2007.

12. Abelha L, Muñoz MD, Gonçalves S, Fagundes P, Barbosa DR, Legay LF, Lovisi G. Evaluation of social disablement, psychiatric symptoms and autonomy in long-stay psychiatric patients Rev. psiquiatr. clín. 2006; 33(1):10-17.

13. Vidal CEL, Gontijo ECDM, Bandeira MB. Avaliação das habilidades de vida independente e comportamento social de pacientes psiquiátricos desospitalizados. Rev. psiquiatr. Rio Gd. Sul 2007; 29(3):294-304.

Artigo apresentado em 28/07/2015

Aprovado em 23/01/2016

Versão final apresentada em 25/01/2016 